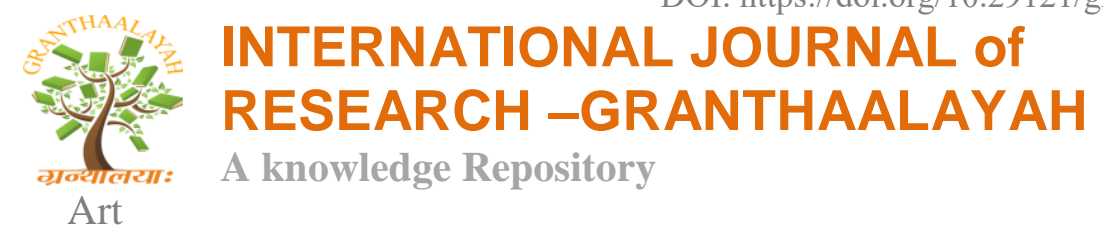

\title{
A COLORFUL DIET IS NEEDED TO ENHANCE ACADEMIC PERFORMANCE OF THE CHILDREN
}

\author{
Dr. Munira M. Hussain \\ Professor Food and Nutrition, Sangita Tomar PhD Scholar \\ Govt. Girls P.G. College Moti Tabela, Indore (M.P) India
}

\section{ABSTRACT}

Colors contain phytochemicals substances occur naturally only in plants and provide health benefits beyond those that essential nutrients provide. A nutritionally adequate diet is essential for optimal growth and development. Childhood and adolescence are periods of continuous growth and development. So, in this study Phytochemical intake of the school going children was computed by counting the number of serving of colourful fruits and vegetables in their diet per week and association of phytochemical intake status with academic performance was found out. Obtained results showed that the distribution of children among different categories of academic performance as per their phytochemical intake status was found significant. Children taking high phytochemical foods were found more in better academic performance category in comparison to children taking low phytochemical foods. Colourful phytonutrients have tremendous health benefits for the brain. Phytonutrients impart colour to fruits and vegetables and are the basis of the recommendation to "eat your colours. The current recommendation of 5-9 servings of fruits and vegetables is not being met with most children. So, taking colourful diet is important for over all wellbeing of the children.

\section{INTRODUCTION}

What does color have to do with diet anyway? One word: phytochemicals. These substances occur naturally only in plants and may provide health benefits beyond those that essential nutrients provide. Color, such as what makes a blueberry so blue, can indicate some of these substances, which are thought to work synergistically with vitamins, minerals, and fiber (all present in fruits and vegetables) in whole foods to promote good health and lower disease risk. A nutritionally adequate diet is essential for optimal growth and development. Childhood and adolescence are periods of continuous growth and development. For the school going children a healthy diet containing all the food groups in required amounts is essential for optimum body composition, $\mathrm{BMI}$ and to reduce the risk of diet-related chronic diseases in later life and prevent vitamin deficiency. Eating more fruits and vegetables help children to maintain a healthy weight, feel better and have more energy. Keeping these facts in mind in present study Dietary phytochemical intake in relation with the nutritional status of school going children was done.

\section{METHODOLOGY}

The Sample: The study was preceded with the selection 300 school children aged 8 - 14 years through purposive sampling method from The Shree Krishna Public school, Tilak Nagar, Indore (MP). Written consent has been taken on from their parents in this regard. 
Data collection: A pre-tested and pre-designed performa was used to collect the information regarding Twenty four hour recall was taken with the help of a format in which the meal and meal timings were mentioned. The phytochemical intake of subjects was assessed by using a food frequency questionnaire. In which names of all the fruits and vegetables available in local markets in different seasons were mentioned. The quantities consumed by the subjects were entered carefully on the sheet. Phytochemical intake of the subjects was computed by counting the number of serving of fruits and vegetables per week. A maximum of 80 servings per week kept as standard as per ICMR recommendations The subjects who had servings $>30 /$ week were considered as low intake group, subjects who had 31-50 servings/week were considered as moderate intake group and the ones with 51-80 servings/week were considered as high intake group. Academic performance of the children was taken from the school records last 2 years average marks/grades.

Statistical Analysis: Mean, Standard Deviation, frequency distribution, percentages and ANOVA were and Chi test have been used for data analysis and making inferences using computer software.

\section{RESULTS}

Phytochemical intake and nutritional status

Table -1

Phytochemical intake status of school going children in relation to the number of servings every week (Mean Value \pm SD and $F$ Value)

\begin{tabular}{|l|l|l|l|l|}
\hline \multirow{3}{*}{ Value } & \multicolumn{2}{|l|}{ Phytochemical Intake Status } & \multirow{2}{*}{ F Value } \\
\cline { 2 - 4 } & $\begin{array}{l}\text { Low } \\
(\mathbf{n}=120)\end{array}$ & $\begin{array}{l}\text { Mod. } \\
(\mathbf{n}=\mathbf{1 0 0})\end{array}$ & $\begin{array}{l}\text { High } \\
(\mathbf{n}=\mathbf{8 0})\end{array}$ & \multirow{2}{*}{ 10.22* } \\
\hline Mean & $\mathbf{2 1 . 5 2}$ & $\mathbf{4 1 . 4 9}$ & $\mathbf{5 8 . 5 7}$ & \\
\hline SD & $\mathbf{6 . 6 8}$ & $\mathbf{5 . 7 1}$ & $\mathbf{4 . 0 4}$ & \\
\hline
\end{tabular}

* Significant at $5 \%$ level

From the above table it is clear that the obtained mean values of the fruits and vegetables servings scores/week consumed by the children adjudged as low, moderate and high phyto-taking groups were respectively found to be $21.52 \pm 6.68,41.49 \pm 5.71$ and $58.57 \pm 4.04$ servings scores out of total 80 servings weekly. Further more it is also indicated that obtained $\mathrm{F}$ value for the difference in mean values is significant at .05 level.

Table -2

Distribution of school going children according to their academic performance and phytochemical intake status (Percentage and Chi Value)

\begin{tabular}{|c|c|c|c|c|}
\hline \multirow{2}{*}{$\begin{array}{l}\text { Academic } \\
\text { Performance (\% } \\
\text { of Marks) }\end{array}$} & \multicolumn{3}{|c|}{ Phytochemical Intake Status } & Chi value \\
\hline & Low $(n=120)$ & $\operatorname{Mod}(n=100)$ & High $(n=80)$ & \multirow{5}{*}{$18.3 * *$} \\
\hline$>90$ & $\mathbf{0 . 8 3}$ & 2 & 5 & \\
\hline $75-90$ & 10 & 13 & 16.25 & \\
\hline $60-75$ & 28.84 & 41 & 46.25 & \\
\hline$<60$ & 60.83 & 44 & 32.5 & \\
\hline
\end{tabular}

$* *$ Significant at $1 \%$ level 


\section{INTERNATIONAL JOURNAL of RESEARCH -GRANTHAALAYAH \\ A knowledge Repository}

Art

It is clear from the above table that obtained Chi value for the distribution of children among different categories of academic performance as per their phytochemical intake status is found significant. It also showed that children taking high phytochemical foods were found more in better academic performance category in comparison to children taking low phytochemical foods. Percentages of children securing $>90 \%$ marks were found increased from low to high phytochemical intake status $(0.83 \%, 2 \%$, and $5 \%$ respectively). Similarly children securing $75 \%$ $90 \%$ and $60 \%-75 \%$ marks were also occurred more with better phytochemical taking status (10\%, $13 \%$ and $16.25 \%$ respectively) and $(28.84 \%, 41 \%$ and $46.25 \%$ respectively). Conversely, in < $60 \%$ category occurrence of children found more to lesser in low to high phyto-taking group $(60.83 \%, 44 \%$, and $32.5 \%)$ respectively.

\section{DISCUSSION}

Colourful phytonutrients have tremendous health benefits for the brain. Phytonutrients impart colour to fruits and vegetables and are the basis of the recommendation to "eat your colours". They are critical for repair and protection of neurons, acting as antioxidants that neutralize damaging free radicals, or protecting memory function. Flavonoids are thought to enhance cognitive function via their neuroprotective properties, enhancing neuronal function and by stimulating neurogenesis). Flavonoids may therefore help to protect against the memory deficits associated with normal ageing as well as the neurodegenerative processes associated with various forms of dementia.

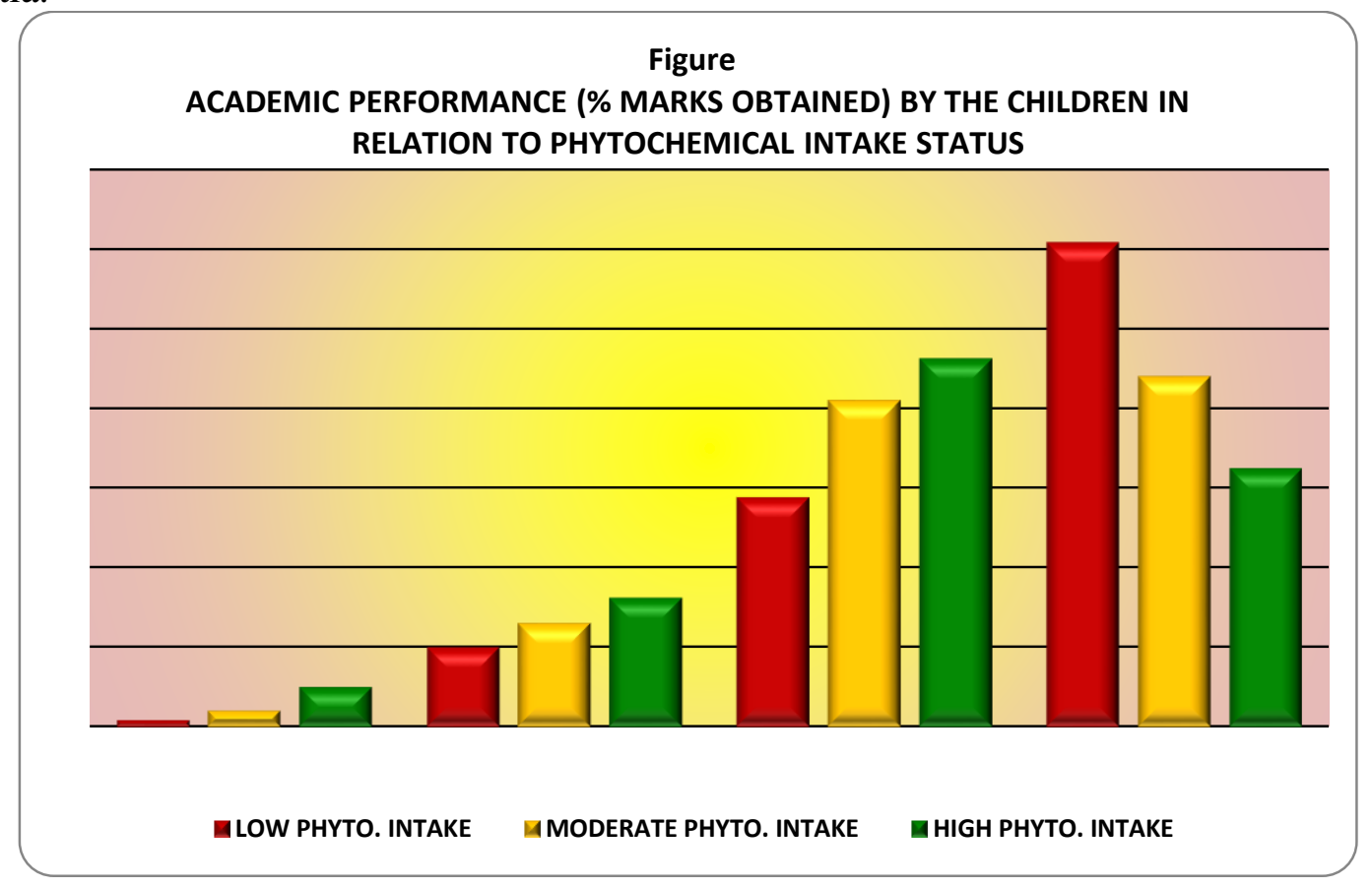


The results of present study clearly shows that the academic performance status in terms of percentages of marks of the subjects of low, moderate and high phytochemical intake status. The graph clearly indicates association of percentage of marks with phytochemical intake. It is evident from the graph that in $>90$ category, children of high and moderate phyto-group were found more than low intake group. In 75-90\% and 60-75\% category same pattern have been seen in which high and moderate group children were more as compared to the low phyto- group. Whereas in $<60 \%$ category low phyto-group children were found more than high and moderate group children. Findings from the present study shows association with dietary intervention studies in which several flavonoid rich plant or food extracts have indicated an ability to improve memory and learning, by protecting vulnerable neurons, enhancing existing neuronal function or by stimulating neuronal regeneration. Flavonoid-rich foods such as blueberry, green tea and Gingko biloba have been shown to be highly effective at reversing age-related deficits in spatial memory and in the enhancement of different aspects of synaptic plasticity, (Casadesus G et al., 2004], a process severely affected by ageing (Burke SN, Barnes CA 2006 Rosenzweig ES, Barnes CA , 2003) Intervention with a $2 \%(\mathrm{w} / \mathrm{w})$ blueberry diet resulted in significant improvements in spatial working memory,(Williams CM et al., 2008]. Dietary levels of pure flavanol monomers (-)epicatechin and (+)-catechin and a pure anthocyanin mixture (reflective of those found in blueberries) are also capable of mediating improvements in spatial working memory in aged animals. Indeed, the changes in spatial memory induced by the pure flavonoids mimicked those induced by whole blueberry, suggesting that the flavonoids are likely to be responsible for the efficacy induced by the whole fruit in vivo (Catarina $\mathrm{R}$ et al.,,2013). These findings were supported by observations that enhancements in spatial memory induced by the flavonoid-rich diets also significantly correlated with increases in hippocampal BDNF protein levels, suggesting that the effect of flavonoids on this neurotrophin may underpin performance on memory tasks.(Van Praag H et at 2007).

Although, the mechanisms by which flavonoids act in the brain are not clear, there is evidence to suggest that blueberry flavonoids can cross the blood-brain barrier (BBB) and reach the central nervous system, where they have the potential to directly regulate gene and protein expression in neurons (Williams CM et al., 2008), However, at present it is unclear as to whether flavonoidinduced memory improvements are mediated exclusively centrally or whether other mechanisms such as stimulations in endothelial function and peripheral blood flow (Schroeter H et al., 2006) also contribute. Such vascular effects are significant since it has been reported that increased cerebrovascular blood flow facilitates proliferation of neuronal cells in the hippocampus and this may influence memory.

So all these evidences clearly indicates that phytochemicals plays significant role in human nutrition, health and wellbeing and have therapeutic role in brain function. So, intake of these functional non nutrient compounds in daily diet should be promoted right from the childhood when the rate of growth is fast and its effects are long lasting.

\section{REFERENCES}




\section{INTERNATIONAL JOURNAL of RESEARCH -GRANTHAALAYAH \\ A knowledge Repository}

Art

1. Burke SN, Barnes CA (2006) Neural plasticity in the ageing brain. Nat Rev Neurosci 7: $30-40$

2. Casadesus G, Shukitt-Hale B, Stellwagen HM, Zhu X, Lee HG, et al. (2004) Modulation of hippocampal plasticity and cognitive behavior by short-term blueberry supplementation in aged rats. Nutr Neurosci 7: 309-316

3. Catarina R, David V, Marcus R, Pierre W-T, Jean M M, Laurie T. B, Claire M. W, and Jeremy P. E. Dietary Levels of Pure Flavonoids Improve Spatial Memory Performance and Increase Hippocampal Brain-Derived Neurotrophic Factor PLoS One. 2013; 8(5): e63535.

4. Palmer TD, Willhoite AR, Gage FH (2000) vascular niche for adult hippocampal neurogenesis. J Comp Neurol 425: 479-494

5. Rosenzweig ES, Barnes CA (2003) Impact of aging on hippocampal function: plasticity, network dynamics, and cognition. Prog Neurobiol 69: 143-179

6. Schroeter H, Heiss C, Balzer J, Kleinbongard P, Keen CL, et al. (2006) (-)-Epicatechin mediates beneficial effects of flavanol-rich cocoa on vascular function in humans. Proc Natl Acad Sci U S A 103: 1024-1029

7. Van Praag H, Lucero MJ, Yeo GW, Stecker K, Heivand N, et al. (2007) Plant-derived flavanol (-)epicatechin enhances angiogenesis and retention of spatial memory in mice. $J$ Neurosci 27: 5869-5878

8. Williams CM, El Mohsen MA, Vauzour D, Rendeiro C, Butler LT, et al. (2008) Blueberryinduced changes in spatial working memory correlate with changes in hippocampal CREB phosphorylation and brain-derived neurotrophic factor (BDNF) levels. Free Radic Biol Med 45: 295-305 